\title{
Being students of Professor Doğan Taner
}

\author{
Ayşegül Fırat ${ }^{1}$ (D), Illkan Tatar ${ }^{1}$ (D), Nihal Apaydın ${ }^{2-5}$ (D) \\ ${ }^{1}$ Department of Anatomy, School of Medicine, Hacettepe University, Ankara, Turkey \\ ${ }^{2}$ Department of Anatomy, School of Medicine, Ankara University, Ankara, Turkey \\ ${ }^{3}$ Department of Multidisciplinary Neuroscience, Institute of Health Sciences, Ankara University, Ankara, Turkey \\ ${ }^{4}$ Brain Research Center (AU-BAUM), Ankara University, Ankara, Turkey \\ ${ }^{5}$ Neuroscience and Neurotechnology Center of Excellence (NÖROM), Ankara, Turkey
}

Anatomy 2021;15(1):97-98 @2021 Turkish Society of Anatomy and Clinical Anatomy (TSACA)

Prof. Dr. Doğan Taner held many administrative positions including deanship for the longest period (1981-1998) in Hacettepe Medical School for many years. He shaped the mission and vision of the medical faculty. He always prioritized the qualified graduate and postgraduate education. As medical students that attended his anatomy lectures we were very lucky. He was a very impressive and extraordinary person. He was an idol for many young medical students and fellows of anatomy. It was the first time that he was calling us as 'doctors' in second year of the medical school. And we calling him as "Prof. DT" or just "DT". His name was mentioned a lot by our peers and they were telling that his lectures should not be missed, but it is good to wear black or white, avoiding colorful things. We understood the reason why, once we attended his lectures.

He was one of the unforgettable figures among our lecturers. No-one can forget the entrance moments of him to the amphitheater to give his lecture. Those amphitheaters, at those time; red and green lecture halls, which is now the cultural center of Hacettepe University, were always dark to have good projection inside making the atmosphere even more spiritual. These moments are of like a divine ceremony. With his black long cloak on his shoulders, followed by the research assistants; one carrying his long stick, the other carrying his lanternslides, he was walking in slow steps from back entrance to the front and greeting the students who are sitting at the first seat of each row. He had such a different and special aura that affected everyone. All of the other faculty members and research assistants of Anatomy Department were joining to his lectures and sitting at the front row. Once he has started his lecture,

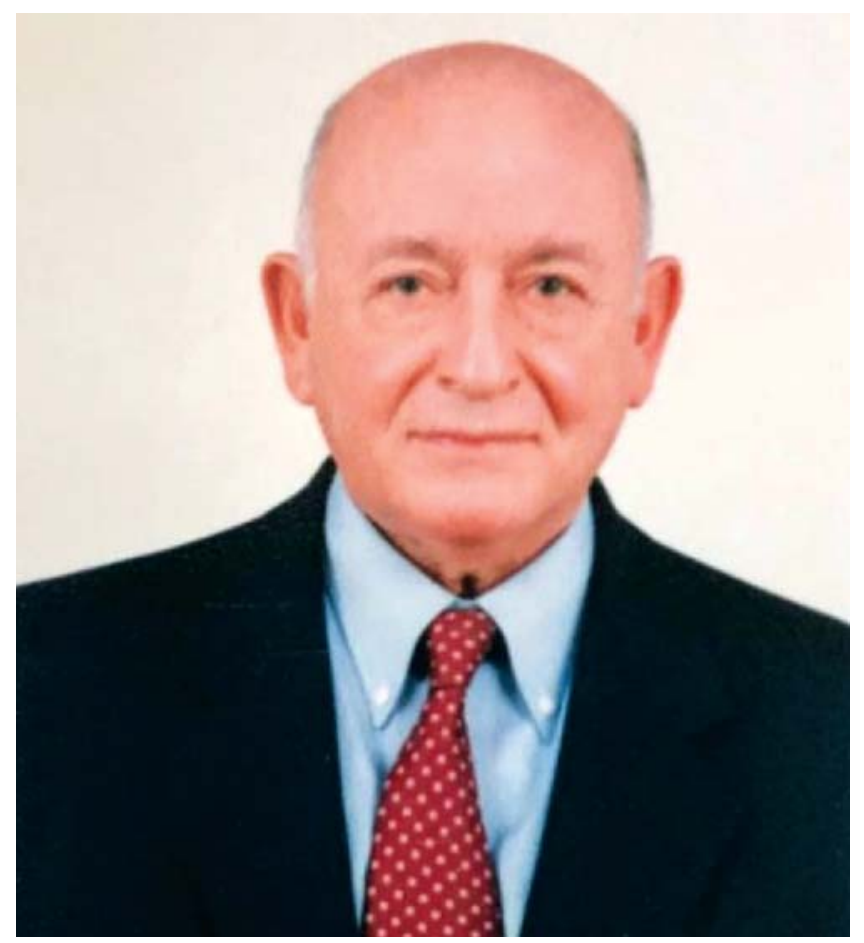

Figure 1. Prof. Doğan Taner (1930-2021), Professor of Anatomy and Chairman, Department of Anatomy, Faculty of Medicine, Hacettepe University, Ankara, Turkey.

no one would say a word and carefully listen not to lose any word spoken by him. He would tell the upcoming slide number and the page numbers from Carpenter textbook, Netter or Sobotta before the assistant change the slide. Since he was not just telling the structure; he had always had a clinical history or a case to be told related with the subject. We learned anatomy from him in 
such a way that we were aware of what we learn and why. There was no way to come to his lectures un-prepared. Because he liked to involve us to his comments and enjoyed discussing and talking with us. He always asked questions making us to analyze and interpret what we learn. He would raise a friend of ours by saying "You; $\mathrm{Mr}$. Doctor, in the red shirt 2 row from the back, can you please answer this question?" After asking his name, where he was from, what his mother and father did, he would ask a very different and difficult question for us at that time, for example about how the proximal and distal parts of a femoral neck fracture would move due to a mid-shaft femoral fracture in a vehicle accident. In the following lessons, most of our classmates preferred to wear unobtrusive colors. However, he would remember our names once he learns, and he would ask by saying "Dr. İlkan even though you are in black t-shirt now, I recognized you and I would like to listen your comments" His questions that he asked in our classical exams were always tricky. It was not possible to answer them without fully understanding the subject. His style may considered as "scary" at those years when we were young, but we than realized that his approach thought us that "anatomy" forms the basis for the practice of medicine and is much more than just memorization of list of names. We realized at early years of our medical education that the network of information needed to visualize the position of structures and an understanding of anato- my contributes to all areas of medicine making it far beyond simple memorization.

He was one of the professors that is excited about teaching and integrating the basic sciences with the clinical practices. He had the experience and enthusiasm about planning the clinical anatomy lectures which would be the first among medical faculties. As a mentor he will be remembered with his emphasis on clinically applied interactive anatomy lectures, giving importance to learning a foreign language and studying regularly. Except for the education, he attached great attention to research. His passion about a good medical student was studying regularly and being punctual.

Although he was an academician who studied cardiology in the USA, he chose basic sciences, morphology as it was then called, with the will and insistence of Hocabey (Prof. İhsan Doğramacı M.D., founder of Hacettepe University), and continued his duty as the dean of Hacettepe University Faculty of Medicine as a professor of basic medical sciences for a very long time. Although we never worked with him due to his retirement, he has always been with us as our founding teacher at department's meetings and gatherings.

We are proud to be his students and more proud to became his colleagues at the end. He was such a great role model and he will always be kept in our memory as an influential mentor and a great anatomist.
ORCID ID:

A. Firat 0000-0001-5105-0057; I. Tatar 0000-0003-2532-8582; N. Apaydın 0000-0002-7680-1766
Correspondence to: Nihal Apaydın, MD, PhD

Department of Anatomy, Ankara University School of Medicine, Sihhiye 06100 Ankara, Turkey

Phone: +90 3125958248

e-mail: napaydin@gmail.com

Conflict of interest statement: No conflicts declared.

This is an open access article distributed under the terms of the Creative Commons Attribution-NonCommercial-NoDerivs 4.0 Unported (CC BY-NCND4.0) Licence (http://creativecommons.org/licenses/by-nc-nd/4.0/) which permits unrestricted noncommercial use, distribution, and reproduction in any medium, provided the original work is properly cited. How to cite this article: Fırat A, Tatar İ, Apaydın N. Being students of Professor Doğan Taner. Anatomy 2021;15(1):97-98. 